\title{
Análise radiológica da veia cava caudal em ratos Wistar ${ }^{1}$
}

\author{
Radiologic analyses of caudal vein in Wistar rats
}

\author{
Luciano Rodrigues Schmidt ${ }^{2}$, Edson José Cardoso ${ }^{3}$, Rogério Rodrigues Schmidt ${ }^{4}$, Carlos Alberto \\ Justo e Silva ${ }^{5}$, Armando José d'Acampora ${ }^{6}$
}

1. Trabalho realizado no Laboratório de Técnica Operatória e Cirurgia Experimental da Universidade Federal de Santa Catarina (UFSC).

2. Cirurgião Vascular do Hospital Universitário (HU)-UFSC.

3. Professor Titular de Cirurgia Vascular da UFSC, Doutor em Técnica Operatória e Cirurgia Experimental pela Universidade Federal de São Paulo - Escola Paulista de Medicina (UNIFESP-EPM).

4. Médico Residente em Clínica Médica do HU-UFSC.

5. Professor Adjunto de Técnica Operatória e Cirurgia Experimental, Doutor em Técnica Operatória e Cirurgia Experimental pela UNIFESP-EPM.

6. Professor Adjunto, Doutor em Técnica Operatória e Cirurgia Experimental pela UNIFESP-EPM. Líder do Grupo TOCE/ UFSC.

\section{RESUMO}

OBJETIVO: Apresentar um método de estudo angiográfico da veia cava caudal em ratos.

MÉTODOS: Foram utilizados 24 ratos Wistar machos, com peso entre 300 a 350 gramas. Os animais foram operados com anestesia geral, utilizando-se injeção intraperiotoneal da solução de Cloridrato Ketamina e Cloridrato de 2-(2,6- xilidino) -5,6- dihidro-4H-1,3-tiazina. O contraste iodado foi injetado na veia dorsal do pênis do rato, utilizando uma agulha de calibre 21 acoplada ao sistema Butterfly ${ }^{\circledR}$ de infusão. O método de cavografia foi testado, no $15^{\circ}$ dia de pós-operatório, em três grupos de 6 animais. O Grupo I foi o controle. Nos grupos II e III os animais foram submetidos respectivamente à ligadura da veia cava caudal acima e abaixo da desembocadura das veias íleo-lombares. No grupo IV à ligadura da veia ilíaca direita.

RESULTADOS: Os exames flebográficos realizados permitiram observar a anatomia e a perviedade das veias que formam o sistema cava, e a circulação colateral desenvolvida, de todos os animais estudados.

CONCLUSÃO: A cavografia por via peniana, permite a visibilidade das vias ilíacas e cava caudal, bem como a circulação colateral desenvolvida, em ratos machos.

DESCRITORES: Cavografia. Angiografia. Ratos.

\section{ABSTRACT}

PURPOSE: To present an angiographic method, to visualize the cava and iliac veins in rats, emphasizing the colateral circulation, developed after interrupting the venous flow.

METHODS: Twenty four male Wistar rats were studied, weighting 300 to $350 \mathrm{~g}$. the access used to injection of the iodined contrast, necessary to the radiologic study, was the dorsal vein of the penis. The method of cavography was tested at the $15^{\text {th }}$ postoperative day, in three groups of six animals.

RESULTS: The group I is control. In groups II and III the animals were submitted respectively of ligature of the caudal vena cava above and below of the iliolumbar veins. In group IV they were submitted to the ligature of the right iliac vein, besides of control group that was not operated. 
CONCLUSION: The cavography with the injection in the penile vein, is capable of viewing the iliac vein and caudal vena cava, as well as the colateral circulation developed in cases the blood flow was interrupted in these vessels.

KEY WORDS: Cavography. Angiography. Rats.

\section{Introdução}

Após a descoberta dos raios-X por Roentgen em 1865, iniciou-se estudos da circulação pela injeção intravascular de substâncias radiopacas. Em 1910, Franck e Alwens injetaram solução oleosa de bismuto para estudar fluorocopicamente o fluxo sanguíneo nas veias, coração e pulmões de coelhos e cães, utilizando drogas de alta toxicidade. ${ }^{1,2}$ Heuser, em 1929, realizou o primeiro estudo contrastado em humanos, injetando iodeto de potássio na veia dorsal da mão de uma criança portadora de sífilis congênita ${ }^{3}$.

Os contrastes iodados com menor osmolaridade e toxicidade passaram a ser largamente utilizados nas colecistografias, urografias venosas, cavidades cardíacas e grandes vasos. Modernamente, os contrastes tri-iodados e mais recentemente, substâncias com seis átomos de iodo foram introduzidas na prática médica, permitindo a realização de exames com menor risco aos pacientes².

Especificamente em ratos, foi Salaman, em 1969 e Ekelund e Olin, em 1970, que estudaram o sistema arterial do animal pela cateterização da artéria femoral, procedimento delicado e de difícil utilização para exames repetidos ou seriados ${ }^{4,5}$.

Kreel e col. ${ }^{6}$ apresentaram o estudo radiológico da árvore arterial e venosa dos ratos injetando o contraste por punção percutânea cardíaca, pela veia dorsal do pênis e canulação da veia jugular interna. Realizaram também esplenovenografia, puncionando diretamente o baço.

O estudo ora apresentado utiliza a veia dorsal do pênis ${ }^{7}$ para injeção do contraste necessário à realização de exame flebográfico em ratos, procurando destacar as alterações do fluxo sanguíneo que ocorrem após ligaduras da veias cava caudal e ilíaca comum direita, com o objetivo de apresentar o estudo angiográfico da veia cava caudal em ratos, enfatizando a circulação colateral desenvolvida após a interrupção do fluxo venoso.

\section{Métodos}

Foram utilizados 24 ( $\mathrm{n}=24)$ Rattus novergicus, machos da linhagem Wistar, com idade mínima de 180 dias, com peso entre 250 e $300 \mathrm{~g}$, procedentes do Biotério Central da Universidade Federal de Santa Catarina (UFSC). Os animais foram aleatoriamente distribuídos em quatro grupos. O grupo I, denominado controle ( $\mathrm{n}=6$ ), e os demais, II, III, IV, os quais provocou-se a interrupção do fluxo sanguíneo das veias infra- renais $(\mathrm{n}=18)$.

O experimento foi desenvolvido no Laboratório de Técnica Operatória e Cirurgia Experimental da UFSC. Todos os animais foram submetidos a período de adaptação de uma semana, no laboratório, onde permaneceram também no período de pósoperatório, em gaiolas de plástico individuais, até o prazo previsto para o sacrifício. Todos os animais foram mantidos sob luz natural, em temperatura e condições de ruído ambientais, recebendo alimentação própria para a espécie, com acesso livre a dieta e a água durante o experimento.

Os ratos foram identificados e pesados antes da realização do procedimento cirúrgico. Na primeira semana se execução do trabalho, os animais do grupo I foram submetidos ao exame flebográfico.

Os ratos foram submetidos à anestesia geral com solução de Cloridrato Ketamina e Cloridrato de 2(2,6- xilidino) -5,6- dihidro-4H-1,3-tiazina, sendo injetado 0,1 mililitro da solução para cada 100 gramas de peso, administrada por via intravascular na face interna da coxa esquerda.

\section{Grupo I (controle)}

Os animais $(n=6)$ foram submetidos a exame angiográfico, das veias ilíacas e da cava caudal infra e supra renais. Utilizou-se a veia dorsal do pênis como via de acesso, facilmente identificada após a exposição da glande pela mobilização do prepúcio. Puncionouse a veia com agulha calibre $21 \mathrm{G}$ acoplada ao sistema de infusão (Butterfly ${ }^{\circledR}$ ) através do qual foi injetado 
1,0 a 2,0 mililitros de diatrizoato de sódio a 50\% (Hypaque ${ }^{\circledR}$ ), no momento em que eram obtidas as radiografias.

\section{Grupos II, III, IV}

Após atingir o plano anestésico, foram posicionados em decúbito dorsal horizontal sobre uma prancha de madeira de $30 \times 35 \mathrm{~cm}$, fixados pelas patas com fitas adesivas. Em seguida foi realizada tricotomia, por arrancamento dos pelos da parede anterior do abdome, antissepsia com álcool iodado a 1\%, e colocação do pano operatório com fenestração de $5 \times 3$ centímetros.

A incisão xifopubiana foi realizada utilizando-se tesoura de Metzenbaum, interessando a pele e tecido celular subcutâneo. Alaparotomia foi completada com abertura da linha Alba e peritônio juntos. Após, foi posicionado afastador auto-estático de Adson, expondo-se a cavidade peritoneal.

Após inventário da cavidade, foram exteriozadas as alças intestinais, que ficaram repousando sobre uma gaze umedecida com solução aquosa de cloreto de sódio a $0,9 \%$. Posicionou-se o microscópio bi-ocular, em aumento de 6 (seis) vezes, para facilitar os tempos operatórios posteriores. Em seguida, abriu-se o retroperitônio expondo-se os grandes vasos, aorta e veia cava, bem como seus principais ramos e

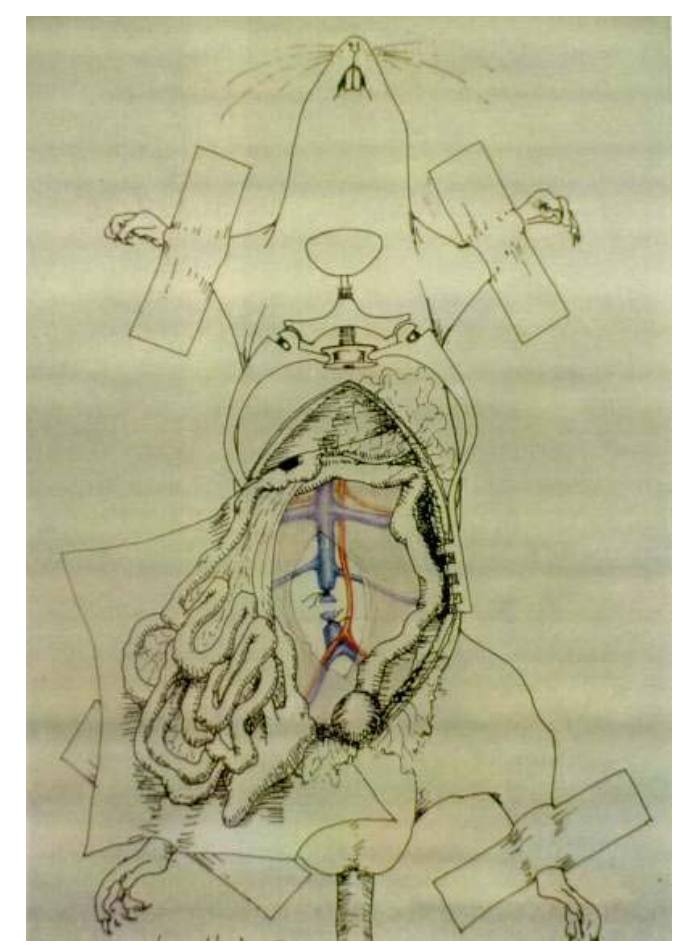

FIGURA 1 - Grupo II, ligadura da veia cava caudal abaixo das veias íleo-lombares tributárias.

Após procedimento dos tempos operatórios específicos de cada grupo de animais, estes foram submetidos à síntese da parede abdominal em dois planos, o músculo-aponeurótico e a pele, respectivamente com sutura contínua ancorada com agulha cilíndrica e com pontos separados com agulha traumática, ambas pré-montadadas com fio monofilamentar de nylon 5-0. Terminada o procedimento operatório, todos os animais permaneceram em ambiente aquecido a 37,5 graus centígrados, até recuperarem sua temperatura basal.

\section{Técnica operatória específica do grupo II}

Estes animais $(\mathrm{n}=6)$ foram submetidos à ligadura dupla da veia cava caudal abaixo da desembocadura das veias íleo-lombares, com fio monofilamentar de nylon 7-0, seguida de secção do vaso entre as ligaduras (Figura 1).

\section{Técnica operatória específica do grupo III}

Neste grupo ( $\mathrm{n}=6$ ), procedeu-se como no grupo II, no entanto a ligadura da veia cava foi posicionada acima da desembocadura das veias íleo-lombares (Figura 2).

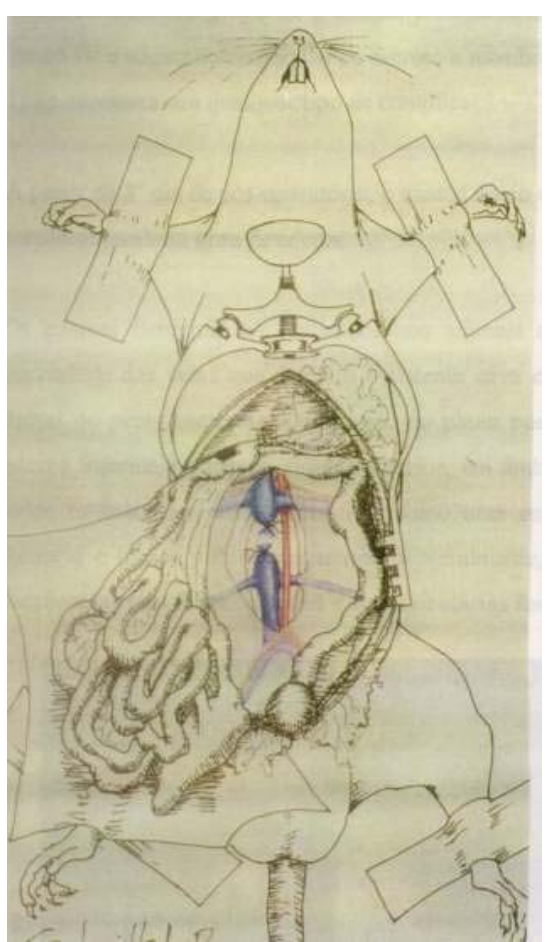

FIGURA 2 - Grupo III, ligadura da veia cava caudal acima das veias íleo-lombares. 


\section{Técnica operatória específica do grupo IV}

Estes animais $(\mathrm{n}=6)$ foram submetidos à ligadura dupla da veia ilíaca comum direita, com fio monofilamentar de nylon 7-0, seguida de secção do vaso (Figura 3).

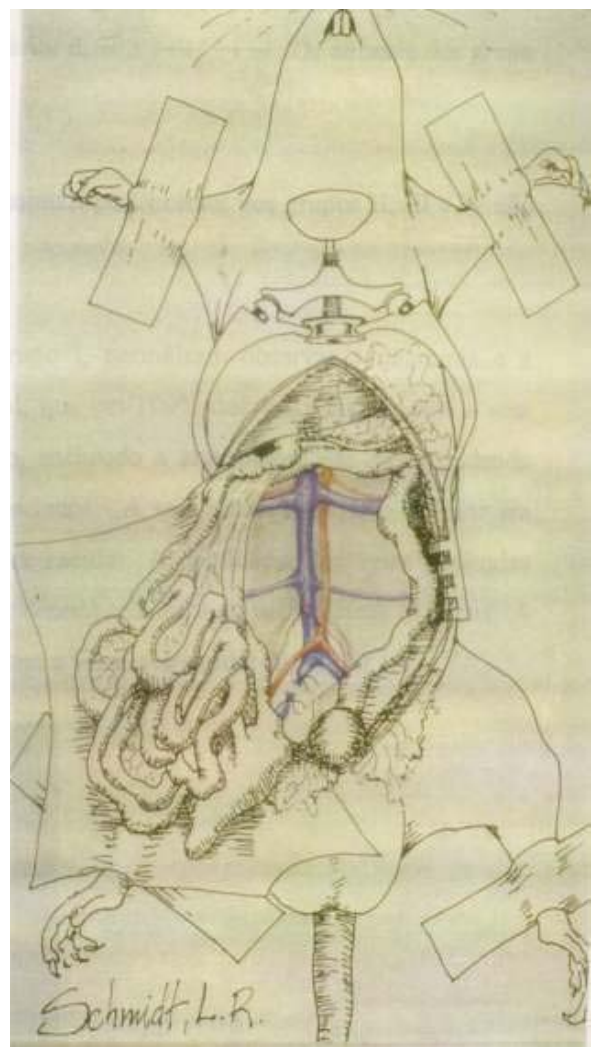

FIGURA3 - Grupo IV, ligadura da veia Ilíaca comum direita.

\section{Pós-operatório}

Os animais foram submetidos a exame clínico diário. Os exames flebográficos foram realizados no $15^{\circ}$ dia de pós-operatório, observando-se a técnica descrita para o grupo I.

Utilizando-se a mesma anestesia do procedimento cirúrgico, os animais foram sacrificados 48 horas após o exame flebográfico.

\section{Resultados}

Na evolução, ocorreu um óbito ao final do exame. No primeiro dia de pós-operatório, os animais pertencentes ao Grupo II, apresentaram edema +++/ ++++ nos membros inferiores e escroto bilateralmente. No grupo III o edema, localizado na mesma região, foi de intensidade $++/++++$. Os animais dos grupos I não apresentaram n qualquer tipo de complicação.

A partir do $8^{\circ}$ dia de pós-operatório, o exame físico dos animais pertencentes aos grupos II, III e IV não constatou nenhum grau de edema.

Os exames flebográficos realizados nos animais do grupo I, permitiram observar a anatomia e a perviedade das veias que formam o sistema cava caudal, que em $100 \%$ dos casos mostraram a veia dorsal do pênis contrastada drenando no plexo pudendo, enchendo a anastomose das veias pudenda interna inferior e pudenda externa inferior, em ambos os lados. A veia pudenda externa inferior em todos os casos apareceu distendida, como uma estrutura sacular. A confluência das veias pudendas formava o tronco púbico-epigástrico bilateralmente, que desembocavam a veia cava caudal (Figura 4).

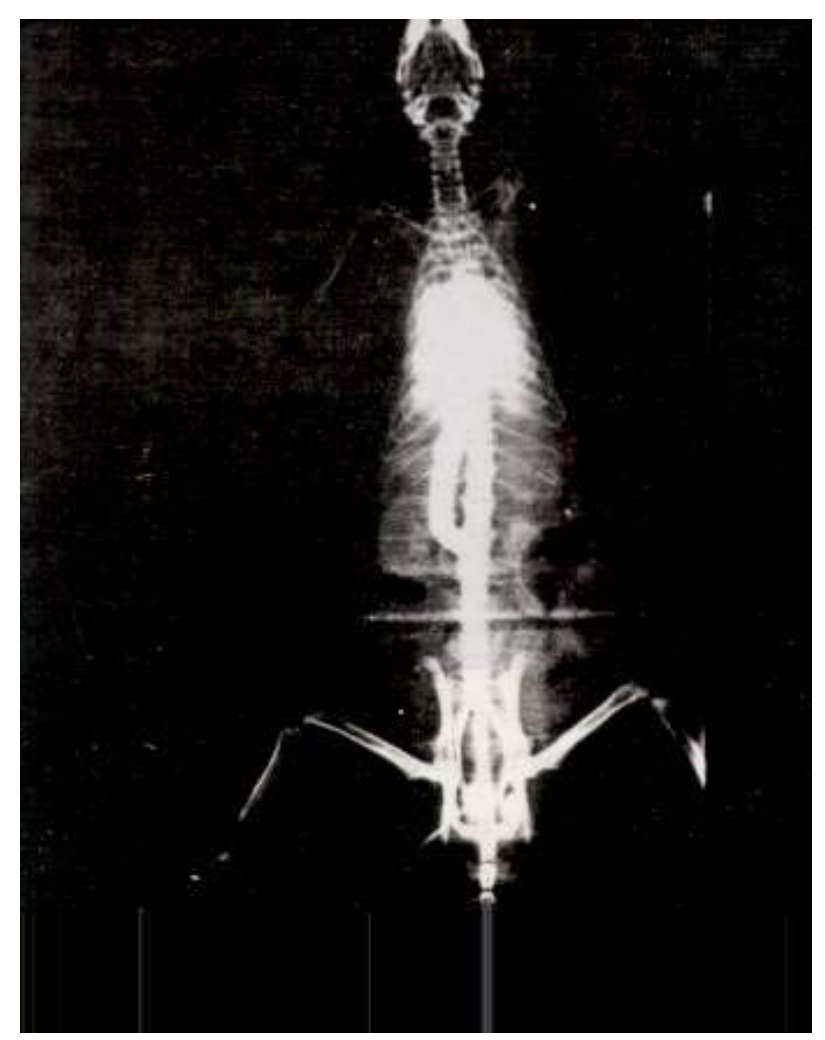

FIGURA 4 - Cavografia normal.

Após a interrupção do fluxo sanguíneo venoso, verificou-se que nos animais pertencentes aos Grupos II e III houve desenvolvimento da circulação colateral, pelas veias gonadais, lombares ascendentes e íleolombares em todos os casos (Figura 5). Em um animal do Grupo III observou-se que a veia testicular direita 
desembocava na veia renal do mesmo lado. No Grupo IV, além destas vias, constatou-se o aparecimento de circulação colateral entre a veia ilíaca e cava do mesmo lado pelo desenvolvimento dos vasos que formam o plexo venoso pélvico como visto na Figura 6.

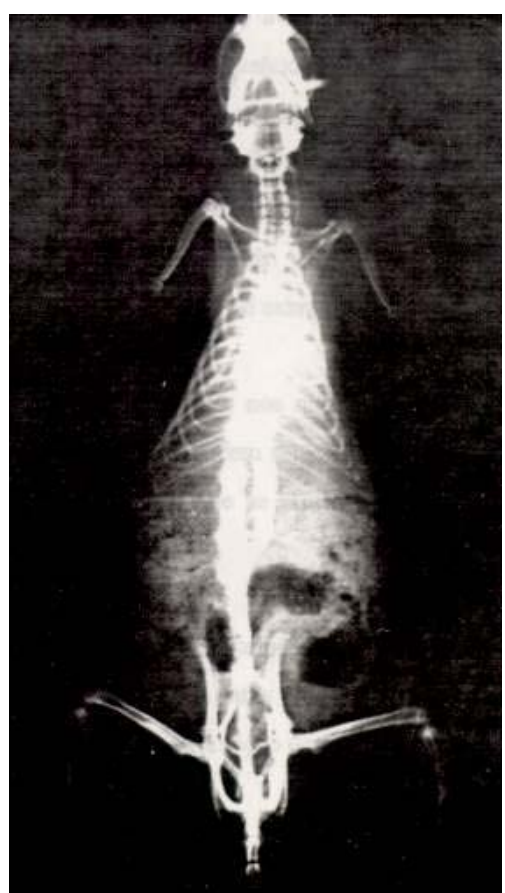

FIGURA 5 - Cavografia após ligadura da veia íleo-lombares.

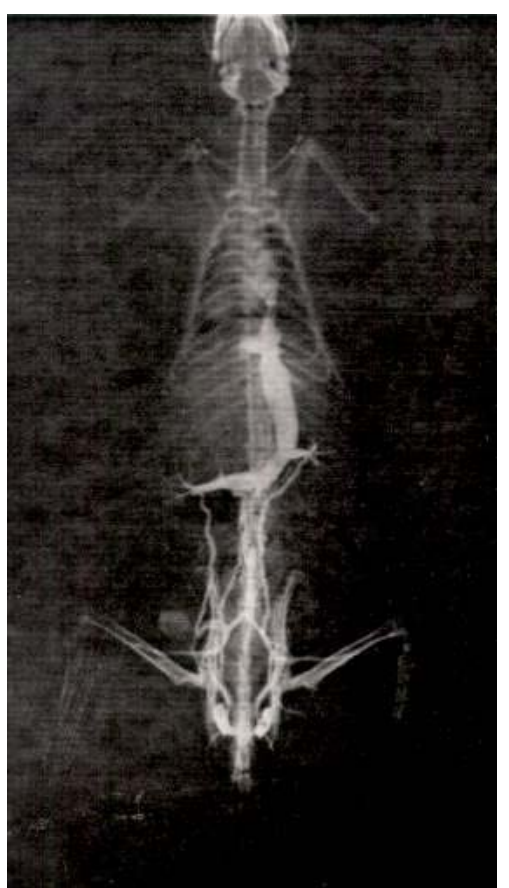

FIGURA 6 - Cavografia após ligadura da caudal logo cava acima logo das veias veia ilíaca.

\section{Discussão}

A cateterização dos vasos sanguíneos em ratos tem sido indicada para a administração de substâncias ou retirada de amostra de sangue. Os vasos mais utilizados são a veia jugular, a carótida, a metatársica dorsal, a sublingual, a veia cava caudal, que é cateterizada pela via femoral, e a veia dorsal do pênis ${ }^{7,8}$.

Kreel e col. ${ }^{6}$ utilizaram esta via para exames angiográficos repetidos, por cinco dias consecutivos, sendo realizadas duas injeções diárias de contraste, observaram dois óbitos em um grupo de 10 animais. Quando realizaram injeção única diária, houve 10\% de óbitos em grupos de 10 ratos e em 20 animais nos quais procedeu-se injeções alternadas, dia sim dia não, a mortalidade foi de $5 \%$. Verificaram uma taxa de sucesso na visibilização da veia cava de $96 \%$ quando utilizada a veia dorsal do pênis para injetar o contraste. Indicaram o método com sendo de escolha para a obtenção de angiografia seriada em ratos.

No presente trabalho, utilizou-se a veia dorsal do pênis para injeção do contraste iodado. Os animais foram submetidos a uma única angiografia. Destes, houve apenas um óbito durante a realização do exame, correspondendo a 4\% (1:24) dos casos. Os demais animais não tiveram complicações no período de seguimento de dois dias, detectáveis ao exame clínico.

A utilização desta via deve ser evitada em ratos de pequeno tamanho, nos quais não é possível a exposição da glande, e restringida a casos especiais pelos danos que podem ser causados à circulação peniana ${ }^{9}$. Tais observações não influíram neste estudo, haja vista que se utilizaram ratos adultos, sacrificados quarenta e oito horas do exame flebográfico.

A injeção intravenosa rápida de quantidades maiores que 1 mililitro de solução salina isotônica pode levar a distúrbio cardiovascular em ratos de 200 gramas $^{1^{\circ}}$. Utilizou-se ratos com peso variando entre 250 a 300 gramas, que suportam a administração de 2 mililitros da solução de diatrizoato de sódio a 50\%.

A veia cava caudal é formada pela fusão das veias ilíacas, situando-se dorsal e ligeiramente caudal à bifurcação da aorta. A veia cava abdominal corre ao longo e a direita da aorta. Na região pélvica, há um plexo venoso em forma circular situado entra a uretra e o soalho pélvico. Este é suprido pela veia dorsal do pênis e veias uretrais, e conectado com as veias 
pudendas interna e externa. Pouco acima da sua formação, a veia cava caudal recebe como tributárias a veias íleo-lombar direita e esquerda. Ao nível de L2 recebe o sangue proveniente das veias renais, aumentando significativamente seu calibre e desviando-se para a direita da coluna ${ }^{6,7}$. Nos animais estudados foi comprovada esta formação anatômica, com algumas variações das veias íleo-lombares, principalmente quanto ao local de deságüe na veia cava. Em um caso (4\%), desembocava na veia renal esquerda e em duas oportunidades constatou-se que era única à direita.

Nos casos estudados, após a interrupção da veia cava abdominal, o fluxo sanguíneo seguiu por vias colaterais, utilizando principalmente a veia testicular esquerda que desemboca na veia renal do mesmo lado, a testicular direita que drena para a veia cava, as veias íleo-lombares e também as veias lombares ascendentes que continuam como veia ázigos. Quando se efetua a ligadura da veia ilíaca comum, além destas vias, há desenvolvimento dos vasos que formam o plexo venoso pélvico.

A ligadura da veia cava leva à formação de edema pélvico e de membros inferiores ${ }^{3}$.

Observou-se, ao exame físico, no primeiro dia de pós operatório dos animais pertencentes aos grupos II e IV, importante edema de escroto e membro inferior. Já no grupo III, este sinal foi menos intenso. No entanto, em todos os três grupos (II, III, IV), apenas no $8^{\circ}$ dia de pós-operatório o edema havia regredido totalmente, talvez, devido à eficácia da circulação colateral desenvolvida.

\section{Conclusão}

A cavografia por via peniana é eficaz para o estudo da circulação colateral em casos de interrupção do fluxo sanguíneo da veia cava e ilíacas em ratos machos.

\section{Referências}

1. Frack O, Alwens W. Kreislaufstudien am Rontgenschirm. Munch Med Wochenschr 1910; 57:1950-8.

2. Dawson P, Graingner R, Pitfield J. The new low-osmolar contrast agents: a simple guide. Clin Radiol 1983; 34:221-4.

3. Heuser, C. Pieloradiografia con ioduro potasico y las injecciones intravenosas de ioduro potasico en radiografia. Sem Med 1919; 26: 424-6.

4. Salaman JR. Renal transplantation in the rat. Br J Surg 1969; 56: 818-22.

5. Ekelund L, Olin T. Catheterisation of arteries in rats. Invest Radiol 1970; 5: 69-74.

6. Kreel L, Green C, Tavill A. Vascular radiology in the rat. $\mathrm{Br}$ J Radiol 1973; 46: 43-7.

7. Chiasson RB. Laboratory anatomy of the white rat. 2ed. Duduque: W.M.C. Brown Company Publishers; 1958.

8. Waynforth HB, Flecknell PA. Experimental and surgical technique in the rat. 2ed. San Diego: Academic Press; 1992.

9. Hebel R, Stromberg MW. Anatomy of laboratory rat. Baltimore: The Williams \& Wilkins; 1976.

10. Hunter JA, Sessions R, Buerger R. Experimental occlusion of the inferior vena cava. Ann Surg 1970;171: 315-21.

Correspondência:

Armando José d'Acampora

Condomínio San Diego, casa 9

88034-420 Florianópolis - SC

acampora@ccs.ufsc.br

Recebimento: 05/06/2004

Revisão: 18/07/2004

Aprovação: 22/08/2004

Conflito de interesse: nenhum

Fonte de financiamento: nenhuma

Como citar este artigo:

Schmidt LR, Cardoso EJ, Schmidt RR, Silva CAJ, d’Acampora, AJ. Análise radiológica da veia cava caudal em ratos Wistar. Acta Cir Bras [serial online] 2004 Set-Out;19(5). Disponível em URL http://www.scielo.br/acb [também em CD-ROM].

\footnotetext{
* Figuras coloridas disponíveis em www.scielo.br/acb
} 